\title{
CORRECTION/REPAIR AS A RESOURCE FOR CO-CONSTRUCTION OF GROUP COMPETENCE
}

\author{
Elizabeth Keating
}

\section{Introduction ${ }^{1}$}

The importance of studying spontaneous, ordinary face-to-face interaction as a key to understanding social organization has been recognized since the work of Garfinkel (1967) and Goffman (1967, 1974). Everyday speech has been found to exhibit an orderliness and organization recognized and oriented to by participants (Schegloff and Sacks 1973; Sacks, Schegloff and Jefferson 1974; Schegloff, Jefferson, and Sacks 1977). As speakers analyze prior turns and produce evidence of their analysis in their own turns, speakers disclose to each other and to overhearers (such as ethnographers) information about social categories, how participants construct context through talk and how recursively context shapes talk (cf. Duranti 1984; Duranti \& Goodwin 1992). What speakers show they find relevant becomes an important basis for studying the collaborative construction of meaning.

This paper will focus on the phenomena of "repair" or correction - ways in which speakers and hearers systematically address recurrent problems in speaking, hearing, and understanding (Schegloff, Jefferson and Sacks 1977). These instances of breakdowns in communication and their resolution are important sites for understanding the processes of social organization. Repair sequences have been shown to be important resources in negotiating identities (Jefferson 1974), in the management of speaking turns and story acceptance during storytelling (Jefferson 1978; Goodwin 1984; Testa 1991), in increasing audience co-participation and responsibility (Besnier 1989), and in indexing spontaneity in otherwise routine talk (Philips 1992).

I will be examining repair or correction sequences in a music rehearsal. I propose that repair or correction strategies facilitate joint construction of the group activity and its collective musical competence and performance. By extensive use of self-corrections, the musicians focus hearer's attention, encourage negotiation, mitigate the divisive potential of other-correction, and, in the case of deictic references, continually reframe the inclusivity of speaker/addressee.

\footnotetext{
1 This paper was initially presented at the Annual Meeting of the American Anthropology Association, Chicago, Illinois, November 1991. I would like to express my appreciation to Alessandro Duranti and Emanuel Schegloff for their insightful comments on the initial version; any errors and omissions remain my own. I would also like to thank the members of the 1965 Bombastic Rockin' Relics Revue and Sometimes Travelin' Band for allowing me to record their rehearsal.
} 


\section{1. "Correction" and "Repair"}

In the context of the music rehearsal, error correction is an important focus of group activity, and instances of other-correction (when a speaker corrects another participant's utterance) are closely related to perceived errors. However, the early work on conversational repair by Sacks, Schegloff, and Jefferson evidences a gradual shift away from the concept of error and the term correction. For example, whereas Sacks first sought to understand what he termed "correction invitation devices" (Lecture 3), and the 1977 article (Schegloff, Jefferson, and Sacks) refers somewhat interchangeably to both "correction" and "repair," by 1979 Schegloff reports that the term "correction" has been replaced by "the more generic rubric 'repair" (1979: 261). This change was made in order to reflect the nature of many self-repairs, in which no error is evident, but speaker modification occurs. Because of the nature of the music practice session, where rectifying performance as well as conversation is relevant, and correction activity is more than a side-sequence, I will use the term other-correction when referring to a speaker's correction of another speaker's utterance in this paper. Use of this term will allow me to include both talk and actions as correctable activities, since the correction of actions is not included in the domain of the concept of "repair" as developed by Schegloff, Jefferson, and Sacks (1977). I will reserve the term "repair" for selfcorrections, i.e. self-repair. I believe, however, that correction of talk and actions may be related, and even interdependent, a theme I would like to develop in future papers.

Before continuing, I will show examples of both self-repair and other-correction. The first example is of self-repair; the speaker corrects her/his utterance as it is produced. The second two examples show other-correction; a hearer perceives an error and initiates correction.

(1) Self-repair example

15 Jim: That's pretty simple and tha-

$16 \quad(.5)$

17 could- could- like- I'm tryin to think-

Note the characteristic cutoffs and restarts in the above example; no errors of speaking are apparent until the speaker (Jim) corrects himself.

The following are two examples of other-correction. The first is an other-initiated correction, which leads to a self-correction. The second is an other-correction both initiated and delivered by another speaker.

(2) Other-initiation of correction (line 05) leading to self-correction (line 06)

$01 \quad$ Russ: $\quad$ Right. And then uh- consistent vocals an' (.)

02 we had a problem hearing Joy on her bah.

03 
04 Jim:

$(?)$

05 Joy:

[

06 Russ:

On her bah?

Um I'm sorry not bah I'm thinkin- not=

(3) Other correction, both initiated and performed by other (line 05 ):

01 Jim: Let's, let's let's go through it just go

02 through it to just that point and then stop.

03

04

05

Sixteen candles, two, three.

06 Jim:

07

08

(1.0)

Three, four.

Three, four alright? heh heh. Three, four, thanks. There's more, one two, three four ((sings)) Happy Birthday Happy Birthday

The subject of conversational repair has been extensively studied. It has been shown, for example, that in conversation American speakers evidence a preference for self-initiated, self-correction and a dispreference for correction by others (Schegloff, Jefferson and Sacks 1977). This dispreference is displayed in structures of conversation, in which opportunities for self-correction precede those for other-correction, and in the observation that other-correction is typically a delayed response. It is notable, however, that in the music rehearsal under study, correction is the core of the activity, a situation which one would expect may have ramifications for the usual preference structure. Indeed other-corrections are many times delivered without delay in the rehearsal, which might be tied to a reliance on deictic reference terms for location of problems in music performance, that is, musicians will reference correctables by terms such as "there" and "now." Weeks (1985) also discusses error correction in an "autocratic" orchestral group. Although in his group only the conductor has the authoritative version of the musical texts, in the "Rockin' Relics" rehearsal, authority and responsibility are distributed among co-participants.

This paper will examine specific occurrences of self-repair and other-correction in the music rehearsal in order to investigate how repair and correction are organized and how such organization helps to constitute the social activity of rehearsing. Transcripts of video excerpts are from a music practice session which took place in February 1990; in these excerpts the musicians are working out dance steps to accompany the song "Rock Around the Clock," and are discussing a song just practiced.

\section{Ethnographic background and data collection}

The band under study is called "The 1965 Bombastic Rockin' Relics Revue and Sometimes Travellin' Band." The band members characterize the band as one which does "copy-tunes," that is, they do not play original work, but selections from other 
artists, those of the 1950's and early 1960's. However, the musicians feel they improve the songs with added vocal harmonies, better equipment, and such things as the addition of dance steps. Members of the band include a lead vocalist, who occasionally plays rhythm guitar (Jim), a lead guitarist (Will), a bass guitarist (Joy), a saxophone player (Russ), and a drummer (John). The band plays for events such as wedding receptions, parties, and class reunions. The musicians rehearse together once per week for four to six hours. All have other (non-music-related) full-time jobs and play in the band in their spare time.

I audiotaped the band rehearsal in 1989 and videotaped a rehearsal in 1990. Additionally, I interviewed each band member informally about such things as music background, experiences with other bands, and personal goals.

\section{Doing "rehearsal"}

Few scholars of either music or social interaction have focused their attention on the rehearsal. Within music scholarship, studies of such activities are generally concerned with methods of improving student skills and most efficient use of practice time (Sloboda 1985), or examining cognitive processes associated with music learning (Koskoff 1988). Though Goffman contributes much to our understanding of the performative nature of social interaction, he characterizes rehearsals as "re-keyings," dependent on live performance to provide the correct interpretive frame (1974: 82). My own position is that rehearsals often are the locus of the co-construction of group identity and performance. Language plays a central role in this activity.

In the strip of interaction under analysis, the musicians are engaged in the activity of coordinating their movements in order to add dance steps to their performance. These dance movements are being proposed, assessed and practiced at the rehearsal. A close look at transcripts of the rehearsal reveals a tension between a need to eliminate errors and social conventions the co-participants share. These conventions emerge in structures of conversation which encourage indirectness and agreement (Pomerantz 1984). A tension also exists because of the constraints on personal autonomy inherent among musicians who must work together to produce a group sound. At one point one musician admonishes another for producing a sound that is "too individual." The achievement of the social activity labeled "rehearsal" necessitates successful manipulation of discourse strategies by actors in a framework where participation rights are evenly distributed. When we look at the interaction, what captures our attention is the recurrent use of self-correction. This seems to be part of a larger set of resources for negotiating decision-making and responsibility, thus facilitating co-construction of a plan for a sequence of dance steps.

As an example of the recurrent use of self-correction, in a sequence of ten utterances by four different musicians, nine utterances contain at least one selfcorrection. Total self-corrections across the ten utterances number twenty-five. This high incidence of repair is not random and I would like to make some observations about it. I will first talk about the occurrence of self-correction in making proposals. 
Secondly, I will discuss the embedding of self-correction in other-correction, and thirdly deictics as the most often repaired linguistic forms.

\subsection{Self-correction and proposals}

Similar to Philips' observation about the speech of judges who routinely use self-repair to project spontaneity as they take guilty pleas from defendants (Philips 1992), it appears that self-correction as used by at least one of the musicians seems to construct an emergent, spontaneous quality in his talk. Repair communicates spontaneity in the case of Jim, the band leader. He is the one who has proposed the idea of dance steps, and as the episode unfolds, it becomes clear that he has predesigned a possible sequence of steps. Rather than bring his ideas forward right away, however, he asks for suggestions from band members in an utterance containing twelve self-corrections. He thus indexes his own proposal as tentative and just-formed. His hesitation invites coparticipation by word search and self-interrupts. Only after the saxophone player, Russ, twice proposes a hip swing movement does Jim bring up his own plan. In proposing his plan second, Jim insures that the musicians have at least two plans from which to make a decision, and that his proposal is seen to emerge from the current discourse.

We will first look at an example of Jim's extensive self-corrections as the musicians begin the discussion of dance steps. For clarity and emphasis, I have grouped instances of each speaker's self-corrections together, that is, I have listed re-starts and re-phrasings under the original "trouble source" or problem portion of the utterance in the transcript; for example, in the excerpt below, lines 01-02, 02-03, 04-05, and 06-07 show an initial phrase which is then cut off and restated.

(4) EXAMPLE 4

01 Jim: how bout on the-

02 on the second lead let's-

03 let's try and put a

04 little show into it 'cause you know we do-

05 we really-

06 like the first

07 about the first six or seven songs

08 we d' really have

09 I've noticed don't have

10 too much of anything in it so

$11 \quad(.5)$

12 when we're playing the bah bah bah bah 'n

13 that's pretty simple right?

$14 \quad(.5)$

15 That's pretty simple and tha-

$16 \quad(.5)$ 
17 could-

18 could-

19 like-

20 I'm tryin to think-

21 well-

22 who has an idea for that? < Let's put it th-

23 does anybody have an idea what we could do for a

24 lead part.

$25 \quad(2.0)$

After Jim's question in line 24, Russ proposes a hip swing, then repeats his proposal. Jim responds with "Yah." and proceeds to propose his own plan, with multiple selfcorrections and hedges, in the example below.

(5) EXAMPLE 5

01 Jim: Yah.

$02 \quad(.2)$

03 I wa-

04 I was almost kinda thinkin like-

05 I was almost kinda thinkin, like bom bom bom

06 bom bom 'n that way you don't have to move=

The co-occurence of hedges with self-correction in the above example is suggestive. G. Lakoff (1975) has noted that hedges can take values that are true and make them false. This suggests that while Jim is proposing a plan, he is at the same time disavowing or modifying it. Self-correction and hedges can frame an event as one of delicate negotiation, thereby reducing polarization and the risks of disallignment. R. Lakoff (1973), Brown (1980), Tannen (1982), C. \& M. Goodwin (1987) and others have reported the use of hedges to modify the force of a speech act as a pattern which recurs in women's speech. Hedges are used by all the band members except, interestingly enough, the woman band member. In a later example, the woman band member (Joy) will also show a difference in her use of self-correction while making a proposal, which is subsequently rejected (Example 7).

Extensive use of "you know" to claim shared knowledge is another feature of talk which co-occurs with self-correction, as noted in the example below, when Russ proposes a hip swing movement.

(6) EXAMPLE 6

01 Russ: I kinda have to stay

02 in-

03 in-

04 you know in front so: if we just do- 
05

06

07 hip swing,

if everybody just does a

By slowing down the rate of speech, multiple self-corrections allow a speaker to perform a checking operation on how recipients might be viewing the proposal, and allow time for the speaker to withdraw the proposal, if disagreement is perceived, or amend the proposal to facilitate understanding or agreement. Thus self-corrections can work to flesh out and negotiate disagreement, and facilitate co-construction of plans. Multiple self-corrections are also one way of monopolizing verbal floor space, an important consideration in a group with egalitarian ideology. There appears to be a positive correlation between the amount of speech used by a member and his perception as the band's leader.

As has been noted by C. Goodwin (1980), Kendon (1985), and Schegloff (1984), self-correction can also function to gain or organize hearer's attention. The rehearsal environment is one in which attention can easily be diverted, as the time between musical numbers in which correction takes place is also used by musicians to adjust amplifiers, go to the bathroom, and get food and water.

The following example is suggestive of a relationship between self-repair and attention-getting strategies. Though Joy does not use cutoffs or restarts in her proposal, she uses "Hey" between two successive repeats of a proposal. For clarity, I have first reproduced Joy's complete utterance out of context (without other speakers' talk), and then I have shown the full transcript (with other speakers' talk).

\section{(7) EXAMPLE 7}

Joy: We could all step o:ut. Hey, (?) we could step out. Forget the mikes:. step out this way < step out in front of your mike because you're not singin', right? just step out here and (?)

In this second segment, Joy's utterance in the context of other speakers' talk is shown (line 10):

$01 \mathrm{Jim}:$ Whu-

02

03

04

05

06

07

08

09 let's ei-

let's either

let's either pi-

let's try the pivot and then

lets try like a-

like kind of like a-

((gestures with guitar))

10 Joy: We c'd all step o:ut. Hey (?) we could step out. 
11

12 Will: ((to Jim))

$13 \quad(.8)$

14 Russ: Do what?

15

16 Joy: Forget the mikes: step o:ut $<$ step out in front $=$ 17

18 Will:
[ That might be kinda weird to do tha:t.

Joy repeats her proposal several times, punctuated by one "hey" in order to get the attention of the other musicians. Extensive repeats recur during other members' proposals, yet more typically occur with self-corrections, which delay delivery of the complete proposal, possibly until hearer's attention has been gained. Joy's utterance is rejected; the account given for rejection is the failure to accommodate one band member in her proposal.

\subsection{Self-correction in other-correction}

Self-correction not only occurs during proposals but is often interspersed in sequences of other-corrections, as shown in the three examples below.

(8) EXAMPLE 8

((Drummer (John) lacks enthusiasm in lead-in to song))

01 Jim: Are you gonna do that?

02

03 John: Yeh.

04

05 Jim: That's oka:y let's bu-

06

07

08

do it-

bu-

do it with (.) punch.(.) mOkay.

(9) EXAMPLE 9

((Russ turns towards drummer $)$ )

01 Russ: Yeah. Yeah.

02 It just punches Jim vocals

03

04

Jim's vocals

just punch Jim's vocals 'n- 
(10) EXAMPLE 10

((Will is talking to the group about a previous song))

01 Will: It seems like it's kinda la-

02

it kina la::gs in there or something

In these examples, the musician correcting the others also corrects himself, with restarts and cut-offs. The speakers use "it" (see lines 1 and 2, example 10) to refer to the song they are all performing. This works toward mitigating other-correction, and indexes inexpertness as a group phenomenon. Self and other categories merge, and responsibility for correction is distributed. As noted above, self-correction has been shown to draw the attention of hearers to the problematic portion of an utterance; thus when self-correction is embedded in other-correction, the focus shifts to the problem ("do it with punch", "punch Jim's vocals" and "it kinda lags") and not the musician who has committed the error. Thus a potentially divisive activity (correction) becomes a source of negotiation and invitation for collaboration. Not every other-correction in the rehearsal is delivered with self-corrections, however, this is a recurrent phenomenon. Other corrections delivered without self-corrections are moderated in other ways, often by other musicians.

\subsection{Self-correction and deixis}

There is an additional way in which self-corrections appear to index co-construction of the group's plan of action. The most often repaired linguistic forms are deictic forms. For example, the subject pronoun of a phrase is often repaired as in the following examples:

(11) EXAMPLE 11 (( $\underline{\text { underline }}$ indicates referent switch))

a) Russ: if we just do- if everybody just does

b) Jim: I mean we- it (.) you know unless- you're

c) Russ: somebod- (.) sa- (.) one way or tother I might get hit.

d) Russ: it could go either way, you can just go either way.

e) Joy: nobody's singin' then, or I'm not singin' then.

f) Jim: [you] try to do it- let's- let's tr- we'll get it so we all go together

This suggests that the orientation and range of the participants in any activity within the 
ongoing rehearsal is repairable, and continually negotiated. The repair of subject referentials is noteworthy in that as the utterance emerges, the current context in which the utterance occurs changes. As Jim replaces subject reference "you" with "we," (example f) he shifts to include himself as both speaker and addressee. Hanks (1990) has drawn our attention to the implications of such constantly shifting indexical ground in his study of Mayan deixis, and pointed to the interactive nature of deictic reference.

Demonstratives and spatial adverbs are also often repaired (shown in boldface below):

(12) EXAMPLE 12

a) Russ: Twar- to your left

b) Joy: Step out this way < step out in front

c) Russ: I kinda have to stay in- in- you know in front

d) Russ: something straight- straight on like that

e) Will: Which way? (.) Right? Go to the right?

It can be noted that terms are routinely changed to a progressively higher level of specificity. By regularly repairing deictic terms, the musicians focus their attention on the relationship of the musicians with respect to each other, both verbally and spatially.

\section{Conclusion}

In conclusion, the musicians appear to use self-correction recurrently as part of a larger set of resources for negotiating decision-making and responsibility and for coconstructing group performance. I have discussed the occurrence of self-correction in making proposals, the embedding of self-correction in other-correction, and deictics as the most often repaired linguistic forms. Self-correction, with its characteristic repeats and self-interruptions appears to gain hearers' attention, invite negotiation, mitigate other-correction, and continually reframe the inclusivity of speaker/addressee. In a potentially divisive atmosphere of individual error correction within a group format, self-correction appears not only to mitigate other-correction, but indexes indecision and invites collaboration. 
Transcription notations (developed by Gail Jefferson)

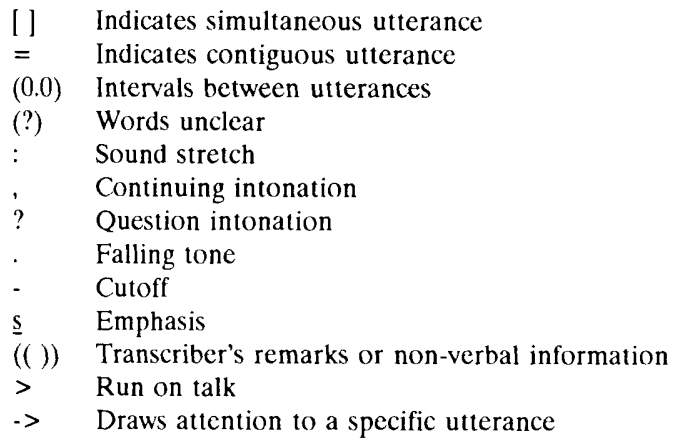

\section{References}

Besnier, N. (1989) Information withholding as a manipulative and collusive strategy in Nukulaelac gossip. Language in Society 18: 315-41.

Brown, P. (1980) How and why are women more polite: some evidence from a Mayan community. In S. McConnell-Ginet, R. Borker, and N. Furman (eds.), Women and language in literature and society.

Duranti, A. (1984) Lauga and talanoaga: two speech genres in a Samoan political event. In D.L. Brenneis and F. Myers (eds.) Dangerous words: language and politics in the pacific.

Duranti, A. and C. Goodwin (1992) Rethinking context. Cambridge: Cambridge University Press.

Garfinkel, H. (1967) Studies in ethnomethodology. Englewood Cliffs: Prentice Hall.

Goffman, E. (1967) Interaction ritual: essays in face to face behavior. Garden City, New York: Doubleday.

Goffman, E. (1974) Frame analysis. Cambridge: Harvard University Press.

Goodwin, C. (1980) Restarts, pauses, and the achievement of a state of mutual gaze at turn-beginning. Sociological inquiry 50: 3-4.

Goodwin, C. (1984) Notes on story structure and the organization of participation. In J.M. Atkinson and J. Heritage (eds.) Structures of social action. Cambridge: Cambridge University Press.

Goodwin. M. H. and C. Goodwin (1987) Children's arguing. In S. Philips, S. Steele \& C. Tanz (eds.) Language, gender \& sex in comparative perspective.

Gumperz, John and Dell Hymes (eds.) (1972/1988) Directions in sociolinguistics: the ethnography of communication. New York: Basil Blackwell.

Hanks, W. (1990) Referential practice. Chicago: University of Chicago Press. 
Jefferson, G. (1972) Side sequences. In D. Sudnow (ed.), Studies in social interaction. New York: Free Press.

Jefferson, G. (1974) Error correction as an interactional resource. Language in society 3:2. 181-200.

Jefferson, G. (1978) "Sequential aspects of storytelling in conversation." In J. Schenkein (ed.) Studies in the organization of conversational interaction. New York: Academic Press, 219-248.

Kendon, Adam (1985) Behavioral foundations for frame attunement in interaction. In G.P. Ginsburg, M. Brenner, M. Von Cranach (eds.), Discovery strategies in the psychology of action. New York: Academic Press.

Koskoff, Ellen (1988) Cognitive strategies in rehearsal. Selected reports in ethnomusicology, Vol. 7.

Lakoff, G. (1975) Hedges: a study in meaning criteria and the logic of fuzzy concepts. In D. Hockney, W. Harper, \& B. Freed (eds.), Contemporary research in philosophical logic and linguistic semantics.

Lakoff, R. (1973) Language and women's place. Language in society 2: 45-80.

Maltz, D. and R. A. Borker. (1982) A cultural approach to male-female miscommunication. In John Gumperz (ed.), Language and social identity. Cambridge: Cambridge University Press.

Philips, S. (1992) The routinization of repair in courtroom discourse. In A. Duranti, C. Goodwin (eds.), Rethinking context. Cambridge: Cambridge University Press.

Pomerantz, A. (1984) Agreeing and disagreeing with assessments: some features of preferred/dispreferred turn shapes. In J.M. Atkinson and J. Heritage (eds.), Structures of social action. Cambridge: Cambridge University Press, pp. 57-101.

Sacks, H. (1967) Lecture 3, Spring Quarter.

Sacks, H., E.A. Schegloff, and G. Jefferson (1974) A simplest systematics for the organization of turntaking for conversation. Language 50: 696-735.

Schegloff, E. (1979) The relevance of repair to syntax-for-conversation. In T. Givon (ed.) Syntax and Semantics 12: Discourse and Syntax. New York: Academic Press.

Schegloff, E. (1984) On some gestures relation to talk. In J. Atkinson and J. Heritage (eds.), Structures of social action. Cambridge: Cambridge University Press, pp. 266-297.

Schegloff, E.A., G. Jefferson, and Sacks, H. (1977) The preference for self-correction in the organization of repair in conversation. Language Vol. 53, No. 2.

Schegloff, E.A. and H. Sacks (1973) Opening up closings. Semiotica 7: 289-327.

Sloboda, J. (1985) The musical mind: the cognitive psychology of music. Oxford: Oxford University Press.

Tannen, D. (1982) Ethnic style in male-female conversation. In John Gumperz (ed.), Language and social identity. Cambridge: Cambridge University Press.

Testa, R. (1991) Negotiating stories: strategic repair in Italian multi-party talk. Pragmatics 1.3: 345-370. 
Weeks, P. (1985) Error correction techniques and sequences in instructional settings: toward a comparative framework. Human studies 8: 195-233. 